\title{
Speed models and criteria for assessing traffic performance on two-lane highways
}

\author{
Janusz Chodur ${ }^{1}$, and Krzysztof Ostrowski ${ }^{1, *}$ \\ ${ }^{1}$ Cracow University of Technology, Faculty of Civil Engineering, 31-155 Cracow, Warszawska Street 24, Poland
}

\begin{abstract}
In the widely used HCM and HBS assessment methods of the traffic performance of two-lane highways speed models are an essential element of the analytical methodology. Differences in the approach to analyses, as well as differing numbers of determinants taken into account and criteria used to assess traffic performance may all produce disparate results and reduce the practicality of the application of these methods. The paper compares the HCM and HBS speed models and demonstrates key differences in their approach to the impact of traffic volume, the share of heavy vehicles and longitudinal gradients of the road. The assessment of traffic performance by both methods also demonstrates significant differences in assessments, especially in more adverse road and traffic conditions. The paper will also show assumptions underlying the choice of research sites, methods of traffic research, databases and selected results of analyses as well as the impact of selected factors on speed and speed regression models.
\end{abstract}

\section{Introduction}

In numerous calculation methods, travel speed is the basic measure of traffic performance on road sections. The latest releases of the American HCM-6 [1] and German HBS-2015 [2] methods use travel speed to assess the traffic performance of two-lane rural roads. In Poland, in order to develop a method for assessing traffic performance and the capacity of two-lane highways, research was undertaken as part of a project entitled "Modern methods of calculating road capacity and assessment of the traffic performance of roads outside municipal agglomerations, including highways" [3] within the framework of the "Development of Road Innovations" program financed by the National Centre for Research and Development and the General Directorate of National Roads and Motorways.

The paper compares speed models and traffic performance assessment criteria in HCM and HBS. In the light of significant discrepancies in assessment between the two methods, the comparison indicates a need to develop a methodology of analysis that will be suitable to Polish conditions. Empirical studies and theoretical analyses which began in 2016 under research project [3] have created premises for the development of travel speed models for Poland's two-lane rural roads.

\section{Vehicle speed models in HCM-6 and HBS-2015}

In HCM-6, the average travel speed of the analysed direction $S_{\mathrm{Td}}$ is determined by; free flow speed in the analysed direction $S_{\mathrm{FF}}[\mathrm{km} / \mathrm{h}]$, demand flow volume of analysed direction $v_{\mathrm{d}}$ and opposing direction $v_{\mathrm{o}}[\mathrm{veh} / \mathrm{h}]$, and the percentage of no-overtaking zones in the analysed $\operatorname{direction} f_{\mathrm{np}}$ :

$$
S_{T d}=S_{F F}-0,0125 \times\left(v_{d}+v_{o}\right)-f_{n p}[\mathrm{~km} / \mathrm{h}]
$$

Free flow speed $S_{\mathrm{FF}}$ depends on the base free flow speed, lane and shoulder widths and access point density.

Demand flow rate in the $d$ (analysis/opposing) direction takes into account demand volume for direction $d \mathrm{~V}_{\mathrm{d}}$ $[\mathrm{veh} / \mathrm{h}]$, peak hour factor PHF, grade adjustment factor $f_{\mathrm{g}}$ and heavy vehicle adjustment factor $f_{\mathrm{HV}}$ :

$$
v_{d}=\frac{V_{d}}{P H F \cdot f_{g} \cdot f_{H V}}[\mathrm{pc} / \mathrm{h}]
$$

The magnitude of longitudinal gradient $f_{\mathrm{g}}$ depends on the type of terrain (level, rolling) and traffic volume on the analysed lane or the value of gradient and its length and traffic volume in the analysed direction.

The impact of heavy and recreational vehicles is calculated using the following formula:

$$
f_{H V}=\frac{1}{1+p_{T} \cdot\left(E_{T}-1\right)+P_{R}\left(E_{R}-1\right)}
$$

where:

$P_{\mathrm{T}}, P_{\mathrm{R}} \quad-$ proportion of heavy/recreational vehicles in the traffic flow,

$E_{\mathrm{T}}, E_{\mathrm{R}} \quad-$ passenger car equivalent replacing trucks/recreational vehicles.

The values of the car equivalents $E_{\mathrm{T}}$ and $E_{\mathrm{R}}$ depend on the type of terrain (level, rolling) and traffic volume on the analysed lane or the value of gradient and its length and traffic volume on the analysed lane.

* Corresponding author: kostrowski@pk.edu.pl 
In HBS-2015, the average passenger car travel speed $S_{\mathrm{pc}}$ in the traffic flow with a share of heavy vehicles is derived from the formula:

$$
S_{p c}=a-b \cdot \sqrt{V}[\mathrm{~km} / \mathrm{h}]
$$

where:

$a, b$ - regression equation parameters,

$V-$ traffic volume on the analysed lane $[\mathrm{veh} / \mathrm{h}]$.

The values of parameters $a$ and $b$ depend on the class of the longitudinal gradient, road curvature class and share of heavy vehicles in the traffic flow. In HBS they are enumerated in a table.

Longitudinal gradient classes (four classes are used) depend on the value of gradient $g$ and its length $L$.

Four road curvature classes were used (the sum of the absolute values of angles of curves over $1 \mathrm{~km}) ; 1-\leq$ $50^{\mathrm{g}}, 2-$ over $50^{\mathrm{g}}$ to $100^{\mathrm{g}}, 3-$ over $100^{\mathrm{g}}$ to $150^{\mathrm{g}}, 4-$ over $150^{\mathrm{g}}$.

In order to determine the speed models in bothHCM and HBS, use is made of the results of simulations (TWOPASS [4], TWOSIM [5], LASI [6]).

The American HCMmethod comprises more factorsthat impact vehicle speeds e.g. width of lane and width of shoulder, density of entries, share of no-overtaking sections and volume of trafficcomingfrom the opposite direction. The GermanHBSmethodtakesintoaccount the road'scurvature as a unique feature. Bothmethodstakeintoaccount the effect of the longitudinal gradient and the share of heavyvehicles in traffic.

Figures 1 and 2 present a comparison of the impact on speed of traffic volume and share of heavyvehiclescalculated by means of bothmethods, in two terrain elevation configurations. In the first case (Fig. 1), according to HCM the road islocated in a flat area, which corresponds to class 1 gradient in the HBSmethod. In the second case (Fig. 2.), the road has a 5\% longitudinal gradient along a one-mile stretch (HCM), which corresponds to class 2 gradient (HBS). In addition, class 1 curvature (HBS), 50/50\% directional distribution and free flow travel speed $S_{\mathrm{F}}=95 \mathrm{~km} / \mathrm{h}$ (HCM) are assumed. It shouldbenotedthat the speed in model (1) is the averagetravel speed of all vehicles, while the speed in model (4) is the averagetravel speed of passenger cars. Speed curvesdeterminedunder the HBSmethodreach the density value of $k=20 \mathrm{veh} / \mathrm{km}$ whichis a marginal value for the free-flow mode. The points of intersection of the speed curveswith the $k=20$ $\mathrm{veh} / \mathrm{km}$ line determinelanecapacity $\left(C_{\mathrm{HV}=0}=1350 \mathrm{veh} / \mathrm{h}\right)$. In HCM, the impact of heavyvehicles on the average speed of the traffic flow in level terrain (Fig. 1) isnegligible and oftenignored. According to HBS, the impact issignificantacross the whole range of traffic volume variations. In $\mathrm{HCM}$, the impact of terrain elevation and the share of heavyvehiclesisincorporatedinto the demand flow rate, whichis not featured in the graph.

Bothmethodsacknowledgethat a considerable vertical alignment gradient of $g=5 \%$ unquestionably has an impact on traffic flow speed (Fig. 2.).

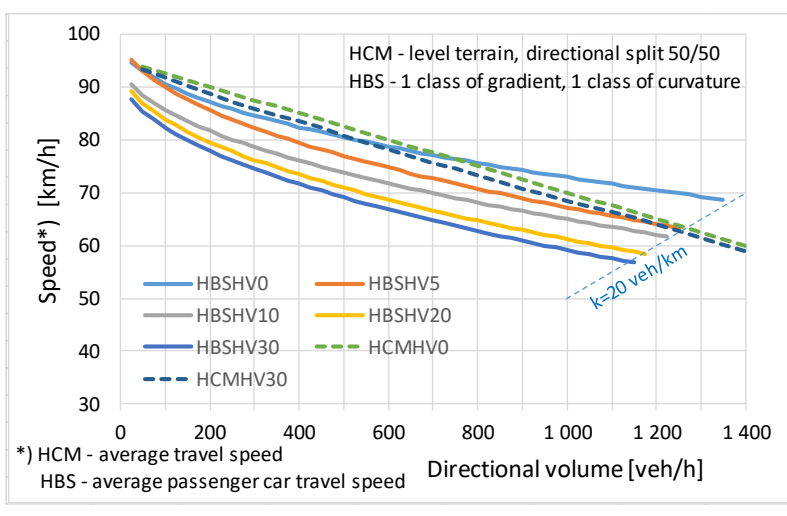

Fig. 1. Comparison of speeds determinedusingmodels (1) and (4) - level terrain road.

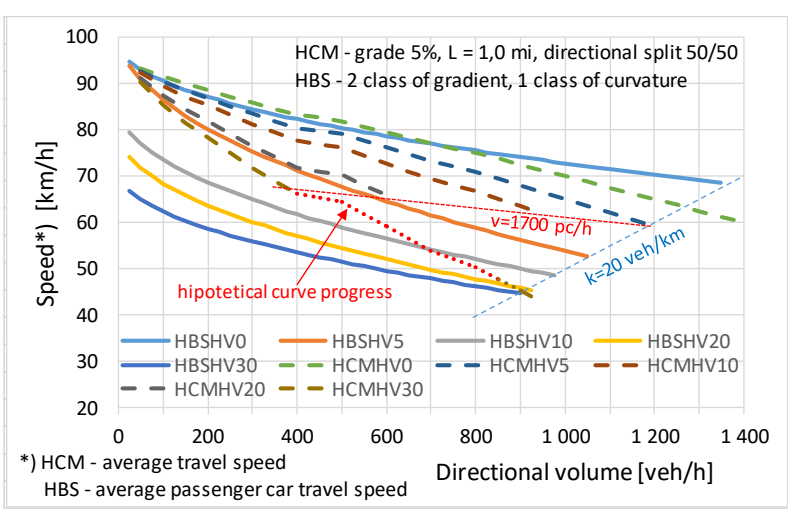

Fig. 2.Comparison of speeds computedusingmodels (1) and (4) - road with 5\% longitudinal gradient over a 1 mile stretch.

The magnitude of this impact isclearlydifferent, however. According to HBS, a share of heavyvehicles at $H V \geq 10 \%$ leads to a significantdecrease in speed even in lowtraffic volumes. In $\mathrm{HCM}$, thisdecreaseoccurs at higher volumes. In this case, the impact of longitudinal gradient and the share of heavyvehiclesisso high in HCMthat the demand flow rate on the upwardslopereaches the marginal value of $1700 \mathrm{pc} / \mathrm{h}$ for one direction as early as at $V=950 \mathrm{veh} / \mathrm{h}$ (for $H V=$ $10 \%$ ), $V=600 \mathrm{veh} / \mathrm{h}$ (for $H V=20 \%$ ) and $V=350 \mathrm{veh} / \mathrm{h}$ (for $H V=30 \%$ ). Hence, the speed curves end in Fig. 2. The figure alsoreveals a hypotheticalshape of the $\mathrm{HCM} H V 30$ speed curveoutside the range of $1700 \mathrm{so} / \mathrm{h}$ demand flow rate.

As indicated by the comparison, the impact of traffic volume, share of heavyvehicles and road's longitudinal gradient on the speed of traffic flow differsmarkedlybetween the twomethods, whichcan cause differencesbetweenassessed values of traffic performance on a given road section.

\section{Assessment criteria under HCM and HBS}

In HCM, traffic performance criteria in terms the level of service (LOS) vary depending on which of the three classes the road is assigned to. For class I roads connecting distant parts of the country (long-distance traffic and relatively high speeds), two measures of traffic conditions were assumed: average travel speed 
and percentage of travel time spent in in platoon traffic. This latter measure is used only for class II roads, which connect to class I roads where drivers do not expect to travel at high speeds. On class III roads, usually passing through small towns, traffic performance is measured in terms of the quotient of average travel speed and average free-flow speed. Marginal values of individual traffic performance measures for LOS ranging from A to $\mathrm{E}$ are presented in a table in the HCM manual $\left(S_{\mathrm{TA} / \mathrm{B}}=55 \mathrm{mi} / \mathrm{h}-\right.$ $88.5 \mathrm{~km} / \mathrm{h}, S_{\mathrm{TB} / \mathrm{C}}=50 \mathrm{mi} / \mathrm{h}-80.5 \mathrm{~km} / \mathrm{h}, S_{\mathrm{TC} / \mathrm{D}}=45 \mathrm{mi} / \mathrm{h}-$ $72.4 \mathrm{~km} / \mathrm{h}, S_{\mathrm{TD} / \mathrm{E}}=40 \mathrm{mi} / \mathrm{h}-64.3 \mathrm{~km} / \mathrm{h}$ ). No values for the measures are specified for the LOS E/F transition. In that case, a separate criterion for traffic volume exceeding the section's capacity $\left(V>_{c}\right)$ is used. In this paper, the authors consider only the case of class I roads with the average travel speed ST (formula 1) as the measure of traffic performance and lane capacity in direction $d$ computed using formula:

$$
c_{d}=1700 \cdot f_{g} \cdot f_{H V}[\mathrm{P} / \mathrm{h}]
$$

In HBS, it is traffic density $\left(k_{\mathrm{A} / \mathrm{B}}=3 \mathrm{veh} / \mathrm{km}, k_{\mathrm{B} / \mathrm{C}}=6\right.$ $\mathrm{veh} / \mathrm{km}, \quad k_{\mathrm{C} / \mathrm{D}}=10 \mathrm{veh} / \mathrm{km}, \quad k_{\mathrm{D} / \mathrm{E}}=15 \mathrm{veh} / \mathrm{km}, \quad k_{\mathrm{E} / \mathrm{F}}=20$ $\mathrm{veh} / \mathrm{km}$ ) that constitutes an LOS criterion. Under the method, graphs were developed to present traffic volume-speed -density relationships for 16 gradient and curvature class combinations. These enable the determination of LOS and the average travel speed of passenger cars against a known traffic volume and share of heavy vehicles. Speed can be an measure of whether the requirements for travel speed of passenger cars assigned to individual classes of national roads are met [7].

Differences in the approach to determining the free-flow level make it impossible to directly compare the ranges of occurrence of given free flow levels as determined by both methods. It is necessary to find a common denominator for traffic performance measures defining LOS in HCM and the lane's traffic density used in HBS. It is possible to calculate the approximate density value for class I roads in the HCM classification based on the average travel speed and traffic volume.

In the comparative analysis of traffic performance assessed by means of both methods, the authors assumed three sections (Ia-Ic) of a class I road characterised by varied road and traffic features (Table 1). Figures $3-5$ show density values at which free flow level changes according to HCM and HBS.

Table 1. Parameters used in analysis of traffic performance.

\begin{tabular}{|l|c|c|c|}
\hline \multicolumn{1}{|c|}{ Parameter: } & Ia & Ib & Ic \\
\hline Section length [m] & 1000 & 1000 & 1000 \\
\hline Lane width [m] & 3,70 & 3,50 & 3,25 \\
\hline Shoulderlength [m] & 1,90 & 1,50 & 0,50 \\
\hline Density of exits [no./km] & 0 & 5 & 20 \\
\hline Type of terrain & flat & rolling & $g=6 \%$ \\
\hline $\begin{array}{l}\text { Share of sections } \\
\text { withovertake ban [\%] }\end{array}$ & 0 & 40 & 80 \\
\hline Design speed [km/h] & 100 & 90 & 80 \\
\hline Share of heavyvehicles [\%] & 0 & 10 & 25 \\
\hline
\end{tabular}

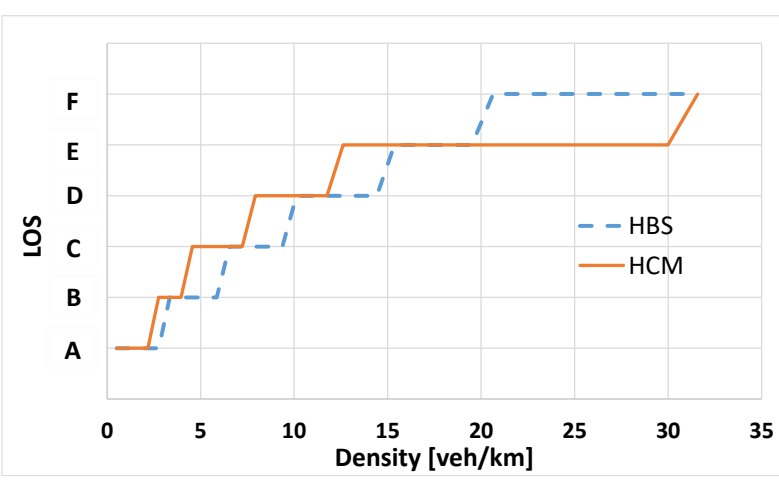

Fig. 3. LOS depending on trafficdensity- section Ia.

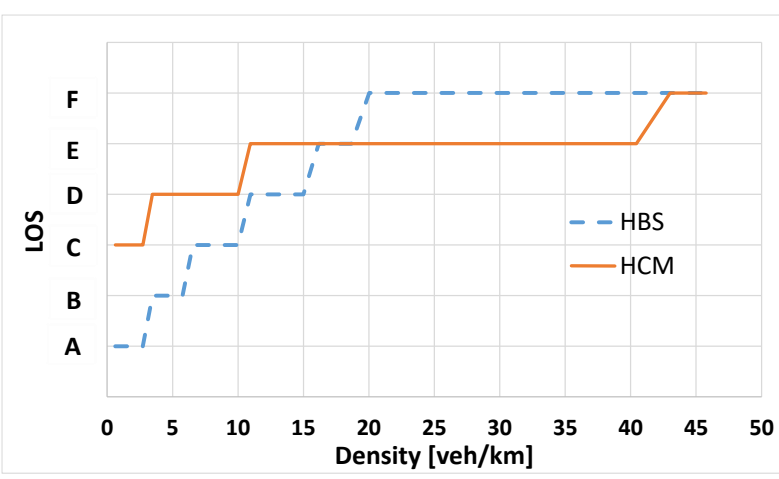

Fig. 4. LOS depending on trafficdensity- section Ib.

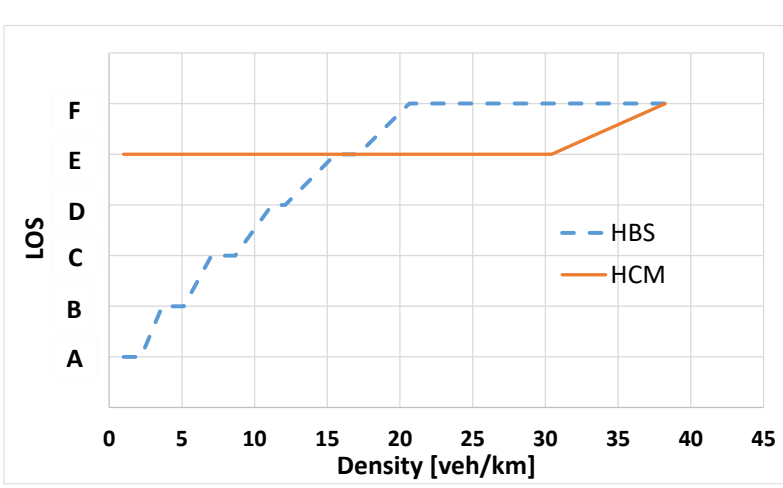

Fig. 5. LOS depending on trafficdensity- section Ic.

As regards a road with favourable parameters (Fig. 3.), the LOS determined based on HCM can be seen to be understated in relation to the values produced by the HBS method. According to HCM, traffic performance deteriorates at lower density values. The criterion of capacity overflow in the HCM method, which determines the transition to forced traffic (LOS F) results in a very wide range of traffic performance corresponding to the LOS E. LOS F will occur after the $30 \mathrm{veh} / \mathrm{km}$ density is exceeded.

With slightly worse road and traffic performance (Fig. 4.) HCM states that it is impossible to achieve LOS A and $\mathrm{B}$, even against very low traffic volumes. This is so because it is impossible to reach the marginal average travel speed of $50 \mathrm{mi} / \mathrm{h}(80.5 \mathrm{~km} / \mathrm{h})$ or over for LOS B. The authors of the HCM method assumed that free flow is disturbed due to a lower speed even when there is a very small number of vehicles on the road. 
In adverse road and traffic conditions (Fig. 5), HCM admits that it is possible to achieve only LOS E, irrespective of traffic volume. This is caused by the inability of achieving correspondingly high average travel speeds at given rad characteristics.

The authors' analysis presents the consequences of differences in the two methods' approach to the issue of free flow. The HCM method focuses more on whether a given road section responds to users' expectations in respect of predetermined criteria. Such expectations may not be met even due to the features of the road itself, even with insignificant traffic volumes.

\section{Empirical research and analysis of factors determining speed on Polish roads}

Based on a review of extant literature [3], comparative analysis of both methods and pilot field tests, the authors specified assumptions which were subsequently used to select road sections on which the travel time and travel speed tests were carried out. Selected assumptions are presented below.

- The tests should be carried out on sections of twolane highways $(1 \times 2)$ located in rural areas (D-43 road sign).

- The minimum length of the section is $800 \mathrm{~m}$ and the maximum $-3000 \mathrm{~m}$,

- The analysed sections should have no pedestrian crossings, railway crossings, signalised roundabouts, or intersections with passage priority on which significant vehicle traffic occurs that limits the freedom of passage on the road with right of way and/or a significant change in traffic intensity on the section before and after the intersection.

- The sections selected for testing should exhibit sizeable variability of traffic intensity during the day and a share of heavy vehicles in traffic. Sections with periodical traffic saturation states are given preference in the analysis.

- The beginning and the end of the test section should be located on a straight section $300 \mathrm{~m}$ before and after a horizontal curve in order to create conditions for free access to and exit from the analysed section.

- A section with significant variation of longitudinal gradient should be divided into shorter sections, at least $800 \mathrm{~m}$ long,

- The test section should have the same cross-section type - lane width of min. $3.0 \mathrm{~m}$ and min. shoulder width of $0.75 \mathrm{~m}$. No sidewalks or bicycle paths are allowed along the road.

Fig. 6. shows the location of 97 test sites on two-lane bidirectional roads. Each site provides data on both directions of travel, so the database consists of 194 directions of movement.

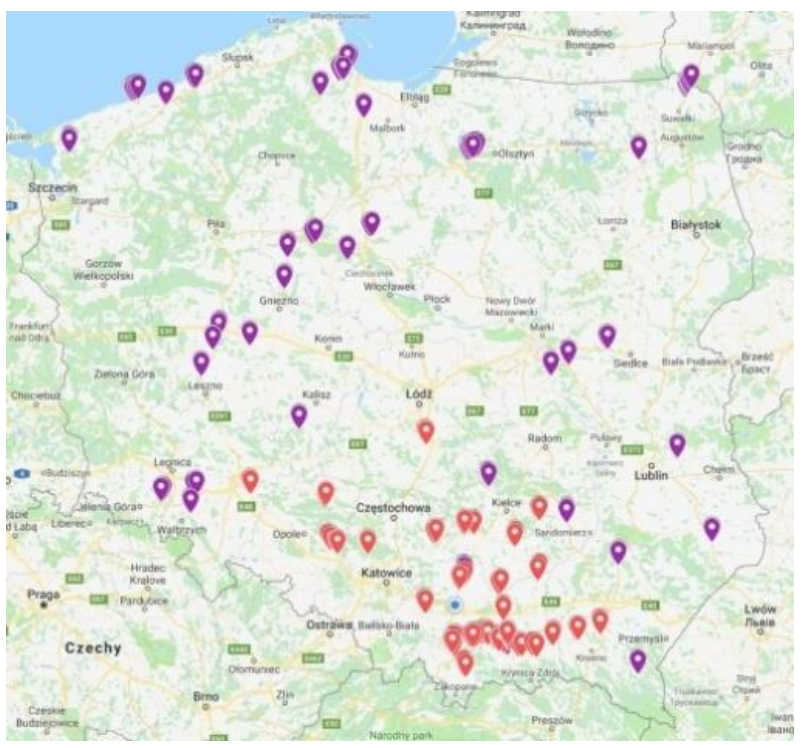

Fig. 6. Location of test sites on two-lanehighwaysin 2016 (red -35 sites) and 2017 (purple -62 site).

2016 and 2017 saw the main traffic studies. The research was carried out mainly in May - September. The assumptions underpinning the research methodology are as follows:

- measurement of traffic intensity in each direction, taking into account the vehicle types at crosssections located at section beginning and end, use of tablets and the Event Counter application. Additionally, the traffic is to be recorded on video cameras,

- rides behind the lead vehicle, with registration on the Polar V650 device. Thanks to a built-in GPS, the equipment recorded changes in the speed of the vehicle along the section and allowed to observe driver behaviour on horizontal curves and at downward and upward slopes,

- inventorying of the analysed road sections and their surroundings.

The measurementswereconducted in the morning (over 4-5 hrs) and afternoon (4-5 hrs) with a technical break during which data were archived and the section was inventoried. Between the two years of research, a total of 281,157 vehicles were recorded in the first direction, and 283,191 vehicles in the second direction. Overall, the database stores 564,348 vehicle records.

Data analysiswaspartially automated using macros written in VisualBasic. The database was prepared in such a way as to enable analysis of the variability of all registered speeds or their average values at of 1,5 and 15 minute intervals, as well as relationships with other traffic parameters and road features.

The databasecontains the following traffic characteristics in relation to each direction i.e. 1-2 and 2-1 and selected time intervals. The traffic characteristics for one direction 1-2 and the road's cross-section are listed below.

- average travel time and speed and their standard deviation,

- traffic intensity at section beginning and end, 
traffic intensity by cross-section at section beginning and end,

- traffic density and standard deviation,

- share of heavy vehicles in traffic on the lane and at the cross-section at section beginning and end,

- number of overtakes along the section,

- number of vehicles entering and exiting from the lane on the analysed section,

- average headway between vehicles at section beginning and end,

- number of trucks at section beginning and end,

- number of trucks with a trailer at section beginning and end,

- average daily traffic in the year according to GPR 2015.

Descriptive and geometric characteristics of the road and its surroundings:

- dataregardingsection's location and measurement (test site's number, direction, date of measurement, voivodship, nearby town, kilometre at section beginning and end, GPS coordinates of the beginning and end of the section, section's length, national (or provincial) road no., weather conditions, condition of road surface, time of day, temperature),

- geometrical data (width of road, lane and shoulder (hard or not) at section beginning and end, number of exits on the left and right, number of horizontal curves, sum of bend angles, curvature and longitudinal gradient (weighted average), percentage of section where overtaking is possible, radiuses and angles of turn of individual horizontal curves, development of road surroundings, speed limits along the section.

The collected data enable analysis of clusters and regression analyses of free flow speeds and travel speed taking into account the distinguished impacts.

\section{Empirical speed model for free flowing vehicles}

In the initial stage of their analyses, the authors performed statistical analyses of travel speed in free flow traffic on the analysed road sections. The analyses were carried out at five-minute intervals and the following assumptions regarding the occurrence of free flow were adopted:

- traffic in the analysed and opposite direction will not exceed $200 \mathrm{veh} / \mathrm{h}$,

- traffic will consist of only passenger vehicles;

- lane width is $3.5 \mathrm{~m}$;

- no hard shoulders.

Cluster analyses and regression analyses were subsequently performed for such a limited database (220 cases), taking into account the influence of curvature and longitudinal gradients and variables describing road surroundings.

During stage one of the research, the authors performed cluster analysis in order to divide variables into groupings, so that variables belonging to one group bear maximum similarity to one other, while others belonging to a different group differ from one other. The hierarchical and agglomeration method was used in which the results are presented in dendrograms. Data providing the following information were included in the analyses: road surroundings and accessibility, i.e. number of exits, existence of barriers and trees directly along the road and in the surroundings away from the road (forests, arable land, dispersed development); road features, i.e. its curvature, longitudinal gradients, number of curves, angles of curve and possibility of overtaking. Fig. 7. presents the results of the analyses of all identified variables. The dendrogram indicates a clear division of factors into two groups. The first, narrower grouping includes factors related to curvature, and the second, broader one, reveals factors related to longitudinal gradient, accessibility, possibility of overtaking and further and nearer road surroundings.

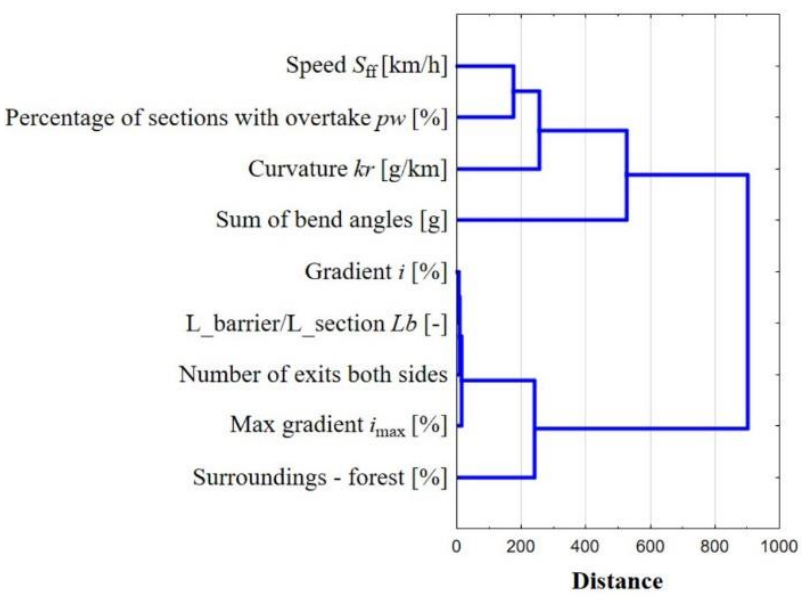

Fig. 7. Dendrogram using Ward's method and Euclidean distance.

Fig. 7. features highly similar variables (closest to one another), which can be aggregated to create ever larger groupings. Several variables accounting for the same impact were introduced into the analyses in order to find similarities between variables, and thus to determine collinearity. Then, clusters should be identified that are clearly different from one another. Additionally the authors introduced into the analyses a variable describing the travel speed under conditions of free flow in order to observe which group of factors better describes its variability. While analysing the elimination of variables, the authors used a discretionary expert method and obtained a limited set of factors (Fig. 8), which should subsequently be subjected to regression analysis in order to identify statistically relevant variables affecting the variability of free-flow speed.

These variables are: weighted average longitudinal gradient $i$; curvature $k r$; percentage of sections with overtake possibility $p w$ and a variable informing about the quotient of the length of barriers relative to the road length $L b$. 


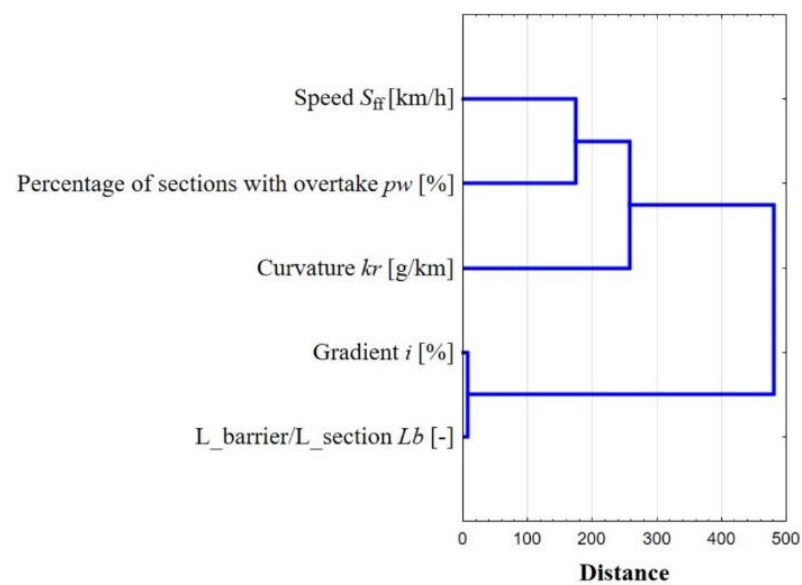

Fig. 8. Dendrogram after data elimination.

Based on regression analyses, it was noticed that the variables $p w$ and $k r$ are strongly correlated. A similar result was obtained for variables $L b$ and $i$. As a result, it is possible to derive two separate formulas taking into account variables $k r$ and $L b$, as these variables are also collinear. The following multiple regression models were obtained for average travel speed under free flow conditions:

$$
S_{f f}=81,7-0,12 \cdot k r[\mathrm{~km} / \mathrm{h}]
$$

for which a regression coefficient of $\mathrm{R}=0.73$ and $\mathrm{a}$ determination of $\mathrm{R}^{2}=0.54$ were obtained. The applicability range of the formula refers to the following range of curvature variability from $0^{\mathrm{g}}$ do $150^{\mathrm{g}}$; and formula:

$$
S_{f f}=65,0+52,1 \cdot L b[\mathrm{~km} / \mathrm{h}]
$$

for which a significantly higher regression coefficient of $\mathrm{R}=0.95$ and determination coefficient of $\mathrm{R}^{2}=0.90$ were obtained. The applicability range of the formula refers to the range of $L b$ variability from 0 to 0.33 , which is rather limited. The existence of the $L b$ variable is associated with both the presence of curvature and significant longitudinal gradients.

The analyses show that the greatest influence on the speed in free flow is exerted by variable $L b$, which is strongly correlated with variables $k r$ and $i$. An attempt to derive a formula that captures the simultaneous impact of curvature $k r$ and longitudinal gradients $i$ failed due to excessive collinearity of both variables. Variable $\mathrm{Kr}$ explains the variability of speed $S_{\mathrm{ff}}$ much better, which is the reason why formula 6 was derived.

\section{Empirical travel speed models}

Travel speed was derived indirectly from the quotient of the distance travelled by the vehicle and the travel time. The analyses were carried out for five-minute intervals, for which the average value of travel speed was determined and other characteristics of traffic, roads and surroundings influencing its variability were determined. The paper [8] presents the general regression formula for travel speed determined for the entire data set. The formula revealed a low determination coefficient of $\mathrm{R}^{2}=0.45$, but indicated statistically significant factors that should be taken into account in further analyses. These analyses were carried out in distinguished groups of variables. The selection of variables used to divide the database was inspired by HCM and HBS methods. The authors decided to introduce a division of regression models in relation to the curvature class and lane width. For the purpose of their analyses the authors adopted four curvature classes, divided according to Polish statutory recommendations, i.e. $1-\leq 89^{\mathrm{g}}, 2-$ over $^{8} 9^{\mathrm{g}}$ to $178^{\mathrm{g}}$,

3 - over $178^{\mathrm{g}}$ to $267^{\mathrm{g}}, 4$ - over $267^{\mathrm{g}}$. The range of variation in the lane width ranges from $2.9 \mathrm{~m}$ to $4.5 \mathrm{~m}$ (including the width of hard shoulders which have a maximum width of $2.5 \mathrm{~m}$ ). The authors developed regression dependencies grouped as follows:

- group 1: curvature class1 and 2, broken down by lane width, i.e. at $\mathrm{w} \leq 3.5 \mathrm{~m}$ and at $\mathrm{w}>3.5 \mathrm{~m}$;

- group 2: curvature class 3 and 4 , broken down by lane width, i.e. at $\leq 3.5 \mathrm{~m}$ and at $\mathrm{w}>3.5 \mathrm{~m}$.

Based on the above assumptions, the following regression formulas were obtained:

group 1; at $\mathrm{w} \leq 3.5 \mathrm{~m}$ :

$$
S_{T}=74,5-0,16 \cdot V+0,09 \cdot p w-0,54 \cdot i
$$

$\mathrm{R}^{2}=0,32$

group 1; at $\mathrm{w}>3.5 \mathrm{~m}$ :

$$
S_{T}=41,91-0,11 \times V+11,69 \times w
$$

$\mathrm{R}^{2}=0,47$

group 2; at $\mathrm{w} \leq 3.5 \mathrm{~m}$ :

$S_{T}=45,35-0,041 \times V+7,30 \times w-0,11 \times|H V \cdot i|(10)$

$\mathrm{R}^{2}=0,59$

group 2; at $\mathrm{w}>3.5 \mathrm{~m}$ :

$S_{T}=89,44-0,26 \cdot V-0,22 \cdot|H V \cdot i|[\mathrm{km} / \mathrm{h}]$

$\mathrm{R}^{2}=0,59$

where:

$V$-average traffic intensity in the analysed direction at 5 min intervals,

$w$-lane width including hard shoulder existence and width,

$H V$-average share of heavy vehicles at $5 \mathrm{~min}$ intervals,

$i$-average weighted longitudinal gradient,

$p w$ - percentage of sections with overtake.

The derived formulas are characterized by a slightly higher coefficient of determination than that given in paper [8]. The goodness of the model's fit to the empirical data is not yet adequate and for the purpose of their further studies the authors plan to introduce an additional division of the database taking into account the impact of longitudinal gradients and resultant interactions of variables (intuitively, the impact of longitudinal gradients and the share of heavy vehicles 
seems to be surprising in model 8). Additional independent variables will be introduced to the analysis to capture the impact of the road surroundings located directly at the edge of the road, as well as those away from it. In the newly developed regression models, the authors plan to substitute the free word with a regression formula for the average speed in free flow (formulas 6 or 7). These further steps of analyses will allow to build models reflecting the actual driver behaviour on Polish two-lane two-way roads.

\section{Conlusions}

As regards traffic performance assessment methods for two-lane, bi-directional roads, the American HCM and German HBS methods differ significantly in terms of the methodology of analysis, factors characterizing the road and road traffic as well as criteria for classification of traffic performance. Due to the standardization of the cross-section of national rural roads in Germany, the HBS method ignores, for example, the impact of the width of the lane and shoulder free of obstacles which is taken into account in the HCM method. Both methods also differ markedly in terms of their approach to the impact of longitudinal gradients and share of heavy vehicle traffic. A comparative analysis of the methods showed that a road's longitudinal gradient and the type of vehicles have a distinctly different effect on the travel speed as measured by either of these methods (Figures 1 and 2). A random comparison of the impact of these factors as reported by the HBS method with the results of empirical research in Poland is presented in paper [8]. Classification of traffic performance in specific road and traffic conditions based on the HCM and HBS methods is clearly different (Figures 3 - 5), and differences are increasingly manifest as the road parameters become inferior (greater longitudinal gradient, curvature and road accessibility). According to HCM, very good traffic conditions are not attainable (LOS A,B) on a narrower road with greater longitudinal gradients, even when traffic volumes are very low. The German method yields completely different results under such conditions.

Detailed comparisons of the most frequently used HCM and HBS methods underpin the need to develop a method based on research results suiting Polish conditions.

In 2016 and 2017, numerous empirical studies were carried out on sections of Polish roads. A database was developed, which was subsequently used to perform statistical analyses, including cluster analyses and regression analyses. In the construction of models, use was made of the knowledge and research experience from similar Polish studies the results of which were recorded in papers [9-11]. The structure of both HCM and HBS and the differences presented in the paper inspired work on the development of a Polish method. The Polish model will incorporate factors that appear in both the German and American methods. In their analysis of factors affecting the variability of average speed in free flow, the authors showed that, in addition to road curvature, drivers' behaviour is affected by the existence of road barriers. The more there are, the more confident drivers feel and the faster they drive. The analysis of regression presented in the article for different groups of lane curvature and width shows that longitudinal gradients have a lower impact on speed than road curvature. A much more important role is played by the interaction between heavy vehicles and weighted average longitudinal gradient, which turned out to be statistically significant. The results of research (goodness of fit) indicate a need for further exploration of different configurations of road, road surroundings and traffic characteristics than those used in the German and American methods in order to obtain a better representation of reality in regression models.

\section{References}

1. TRB, Highway Capacity Manual, Sixth Edition : A Guide for Multimodal Mobility Analysis. Washington, D.C (2017)

2. FGSV (Hrsg.), Kommission Bemessung von Straßenverkehrsanlagen, Handbuch für die Bemessung von Strassenverkehrsanlagen: HBS, Teil L, Köln (2015)

3. Ostrowski K. (project manager), Chodur J. inter alia, Modern methods of calculating the road capacity and assessment of traffic conditions of roadsoutside municipal agglomerations, including express roads. Within the framework of a projectcalledRID I/50 (Road Innovations DevelopmentRID I/50), GdanskKrakow-Warsaw, annual report, 2017

4. Harwood D., W., May A., Anderson I., Leiman L., Archilla A., Capacity and quality of service of twolane highways. Tech. rep., NCHRP Project 3-55 (3), (1999)

5. Kim J,.A Capacity Estimation Method for TwoLane, Two-Way Highways Using simulations Model. JTE, vol.136, Iss. 1, pp. 61-66 (2010)

6. Brilon W., Weiser F., Two-Lane Rural Highways the German Experience, TRB Annual Meeting, TRB 06-1625, Washington, D.C., (2006)

7. Arbeitsgruppe Straßenentwurf, Richtlinien für die Anlage von Landstraßen RAL. Köln: FGSV(2012)

8. Ostrowski K., Chodur J., The impact of selected road and traffic features on travel speed on two lane highway, $5^{\text {th }}$ International Conference on road and rail infrastructure Cetra 2018, pp.1129-1135, Croatia (2018)

9. Jamroz K., et al., Aktualizacja wytycznych obliczania przepustowości dróg zamiejskich. Gdańsk - Warszawa - Bydgoszcz (1986)

10. Szczuraszek T., Prędkość pojazdów w warunkach drogowego ruchu swobodnego, Warszawa (2008)

11. Kempa J., Charakterystyki ruchu swobodnego na krzywoliniowych odcinkach dróg $w$ planie, Wydawnictwa UTP, Bydgoszcz (2008) 